\author{
M. I. Masoud*1, 2 , M. Tashkandi ${ }^{3}$, J. Al-Jarrah ${ }^{3}$, A. I. Z. Farahat ${ }^{4}$ \\ ${ }^{1}$ Northern Border University, Faculty of Engineering, Chemical and Material Engineering Dept., \\ 1321, Arar, Saudi Arabia \\ ${ }^{2}$ On leave from Fayoum University, Faculty of Engineering, Industrial Engineering Dept., \\ Fayoum, Egypt \\ ${ }^{3}$ Northern Border University, Faculty of Engineering, Mechanical Engineering Dept., 1321, \\ Arar, Saudi Arabia \\ ${ }^{4 P}$ Central Metallurgical Research \& Development Institute(CMRDI), Plastic Deformation Dept., \\ P.O.Box 87 Helwan, Egypt \\ *ibrahim_64@yahoo.com
}

\title{
BEHAVIOR OF TRIPLEX STEEL CONTAINING DIFFERENT ALUMINUM CONTENTS
}

\begin{abstract}
Medium-carbon alloy steels containing different aluminum contents were hot forged by $95 \%$ reduction at $1200^{\circ} \mathrm{C}$ followed by air cooling. Optical and scanning electron microscopes were used to investigate the morphologies of the different phases present. An austentizing process followed by water quenching (after hot forging) was carried out to obtain different hardness values. The intensity of the different planes was investigated using X-ray diffraction. The mechanical properties were characterized using tensile and hardness tests. Optical and scanning electron micrographs revealed a great effect of aluminum content on the steel properties. A matrix of bainite and pearlite and traces of ferrite was revealed for hot forged steel type 1 containing $1 \% \mathrm{Al}$. Steel type 2 containing $2 \% \mathrm{Al}$ showed a matrix of pearlite and ferrite with the absence of bainite. The hardness increased with increasing the temperature to a maximum value then decreased for steel containing 1 and $2 \%$ aluminum. After austentizing at $925^{\circ} \mathrm{C}$, the maximum hardness of $649 \mathrm{Hv}$ was recorded for hot forged steel type 2 of $2 \%$ aluminum, while steel type 1 of $1 \%$ aluminum showed a maximum hardness of $531 \mathrm{Hv}$ after austentizing at $1000^{\circ} \mathrm{C}$. Thus, the maximum hardness of hot forged steels decreased with increasing aluminum content. In addition, the maximum tensile and yield strength were decreased by increasing the aluminum content in the steel. The changes in microstructure and mechanical properties of these steels could be explained by the effect of aluminum as a ferrite forming element.
\end{abstract}

Keywords: hot forging, medium carbon steel, microstructure, mechanical properties, hardness

\section{INTRODUCTION}

Free carbide steel exhibits a combination of high strength and good ductility without stress concentration due to carbides. Chromium carbides that can dissolve in the form of nano-size species can contribute to both high strength and good ductility. Addition of Si may cause an ability to dissolve the carbides and can guarantee the uniform distribution of them [1-4]. It was 
reported that quadplex or four phase's steel consists of ferrite, pearlite, bainite and chromium carbides in nano-size [5]. Low-temperature bainite (LTB) is a new type of carbide-free bainite containing superfine-bainitic ferrite plate and retained austenite [6]. The ultra-fine bainite with high strength and ductility by isothermal transformation at low temperature first obtained [7,8]. Low-temperature bainite was obtained and established through isothermal transformation at lowtemperature conditions for several days in some high-carbon high-silicon steels [9, 10]. These studies have attracted amounts of attention due to the brilliant combination of strength, toughness, and ductility. Low-temperature bainite was obtained by adjusting the alloy composition and optimizing heat treatment process in steels with carbon varying from 0.7 to 1.0 $\mathrm{wt} \%$ [11]. However, high carbon concentration reduces the maximum attainable volume fraction of bainitic ferrite. In contrast, low carbon concentration will increase the minimum transformation temperature for bainite formation caused by increasing martensite start (Ms) temperature, which consequently leads to coarser bainite microstructures and thus losing the superiority of the low temperature bainite [12-15]. It has been reported by many researchers that; for medium/low carbon steel, bainite microstructure after heat treatment process in low temperature range had the best microstructure and mechanical properties [16-20]. The goal of this study is to investigate the behavior and properties of hot forged steels containing different aluminum content by studying the microstructure and mechanical properties to obtain high strength and good ductility steel.

\section{MATERIAL AND METHODS}

Steel Type 1 (ST1) and Steel Type 2 (ST2) were produced by induction furnace in Y-block shapes. This Y-block is $4 \mathrm{~cm}$ thick, $20 \mathrm{~cm}$ wide and $25 \mathrm{~cm}$ long. The main difference among the two steel alloys lies in the chemical composition changes due to different aluminum contents being about $1 \%$ for ST1 and about $2 \%$ in ST2 as shown in Table 1.

Table 1. Chemical Composition of ST1and ST2, wt. \%

\begin{tabular}{|c|c|c|c|c|c|c|c|c|}
\hline Alloy & $\mathrm{C}$ & $\mathrm{Si}$ & $\mathrm{Mn}$ & $\mathrm{P}$ & $\mathrm{S}$ & $\mathrm{Cr}$ & $\mathrm{Al}$ & $\mathrm{Cu}$ \\
\hline Alloy1 (ST1) & 0.468 & 1.99 & 1.53 & 0.0404 & 0.0169 & 0.863 & 0.893 & 0.127 \\
\hline Alloy2 (ST2) & 0.393 & 1.78 & 1.47 & 0.0386 & 0.0155 & 0.938 & 1.920 & 0.128 \\
\hline
\end{tabular}

The dilatation curve was carried out to determine the different transformation temperatures, such as AC1, AC3, Bs, Bf, Ms and Mf. Pieces having cross-section of 40x40 $\mathrm{cm}$ and $25 \mathrm{~cm}$ length were cut out from the as cast ST1 and ST2 Y-blocks. These pieces were heated at $1200^{\circ} \mathrm{C}$ for $30 \mathrm{~min}$ followed by air cooling to be hot forged. Figure 1 showed the hot forging process curried out for ST1 and ST2. After hot forging Austentizing followed by water quenching was applied. The purpose of the austentizing process is to introduce different phases (austenite and Ferrite) and to get different mixtures of phases after cooling. Consequently, affecting the final microstructure and hardness of the used steels. Microstructure was observed using Optical and Scanning Electron Microscopes (OM\&SEM) for the as-cast and heat treated steel alloys, ST1 and ST2. The X-ray diffraction and intensity of the different planes was investigated using $\mathrm{Cu}$ 
target filtered radiation at $40 \mathrm{kV}$ and $40 \mathrm{~mA}$. Hardness and tensile tests were carried out for the hot forged ST1 and ST2 after austenitizing at different temperatures.

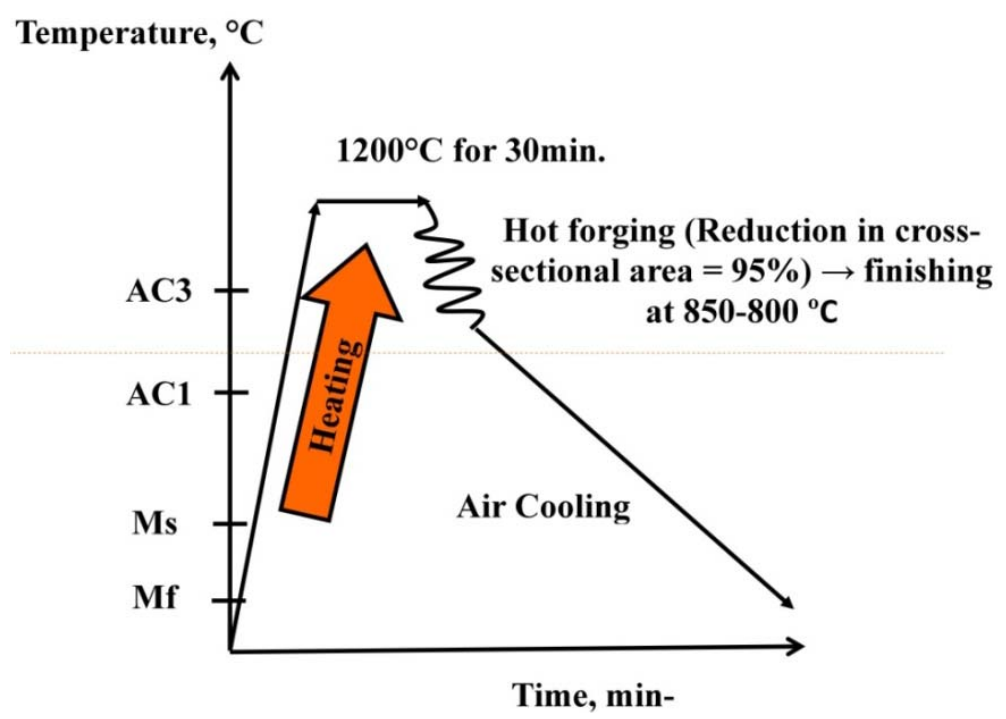

Fig. 1. The hot forging process curried out for ST1 and ST2

\section{RESULTS AND DISCUSSION}

\section{Critical transformation temperatures}

The actual critical transformation temperatures were determined using quench type dilatometer; the results shown in Table 2.

Table 2. Actual critical transformation temperature, ${ }^{\circ} \mathrm{C}$

\begin{tabular}{|c|c|c|c|c|c|c|}
\hline Alloy & AC1 & AC3 & Bs & Bf & Ms & Mf \\
\hline Alloy1 (ST1) & 800 & 850 & 745 & 580 & 333 & 192 \\
\hline Alloy2 (ST2) & 816 & 875 & 738 & 575 & 390 & 240 \\
\hline
\end{tabular}

The results in this Table shows that increasing the aluminum content increases the ferriteaustenite transformation temperatures $\mathrm{AC} 1$ and $\mathrm{AC} 3$ as well as the martensite transformation temperatures Ms and Mf. On the other hand, bainite transformation temperature (Bs, Bf) slightly decreases.

\section{Microstructure of the as-cast steel}

Coarse and heterogeneous phases are present due the cast and cooling conditions of ST1 and ST2 as shown in Fig. 2. The ST1 consists of ferrite-pearlite and very few amount of ferrite on the grain boundaries. While ST2 consists of ferrite-pearlite and more ferrite on the grain boundaries as shown in Fig. 2-(b). This significance in ferrite increase for ST2 could be attributed to the well-known influence of Aluminum as ferrite forming element, see Fig. 3 [20]. 
a)

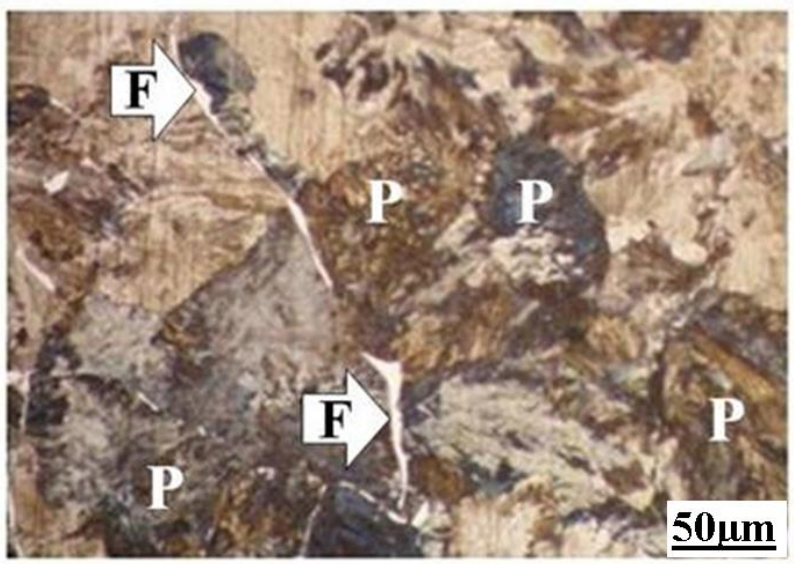

b)

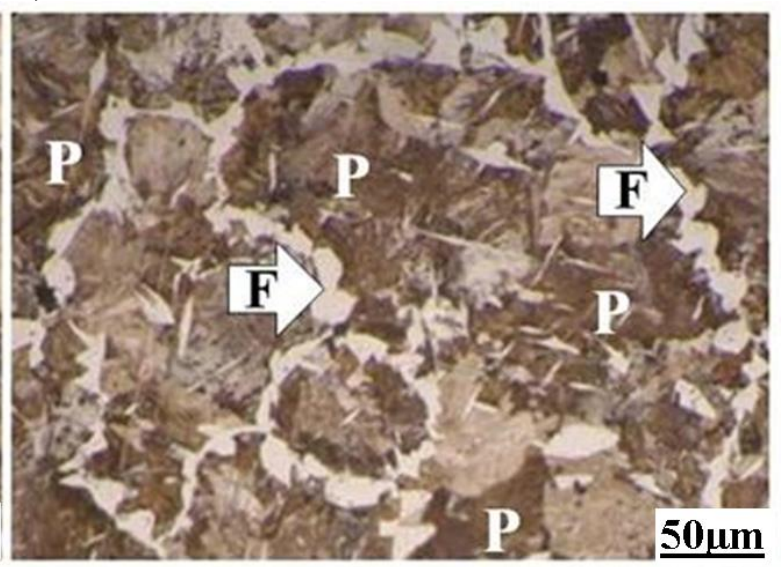

Fig. 2. The microstructure of the as cast steels, (a) ST1and (b) ST2

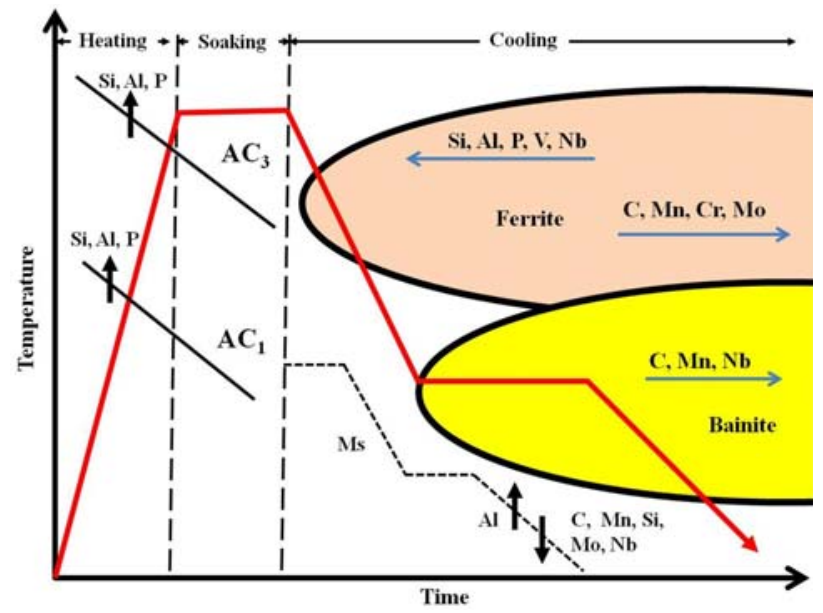

Fig. 3. Alloying elements effect on the ferrite and bainite formation during continuous cooling transformation

\section{Microstructure of hot forged steel}

Figure 4 shows the microstructure of hot forged ST1 and ST2 observed by SEM. A matrix of Bainite (B) and Pearlite (P) were revealed for ST1 with traces of Ferrite (F) along the grain boundaries (see Fig.4 (a). On the other hand, ST2 showed pearlite-ferrite matrix with absence of bainite as shown in Fig.4 (b). It can be concluded that increasing aluminum content highly affects the microstructure of hot forged ST1 and ST2. By using the image analyzer, it was noted that increasing aluminum content highly increases the ferrite volume fraction as shown in Table.3. This result is in a good agreement with the microstructure of the as cast alloys. 
a)

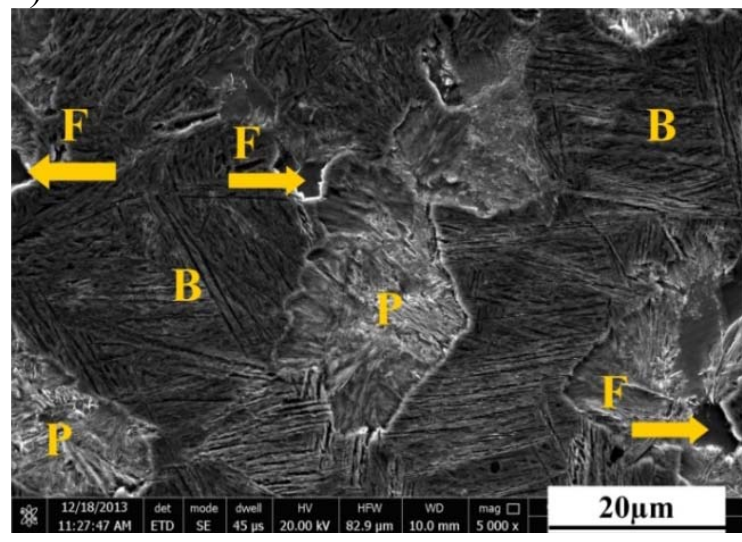

b)

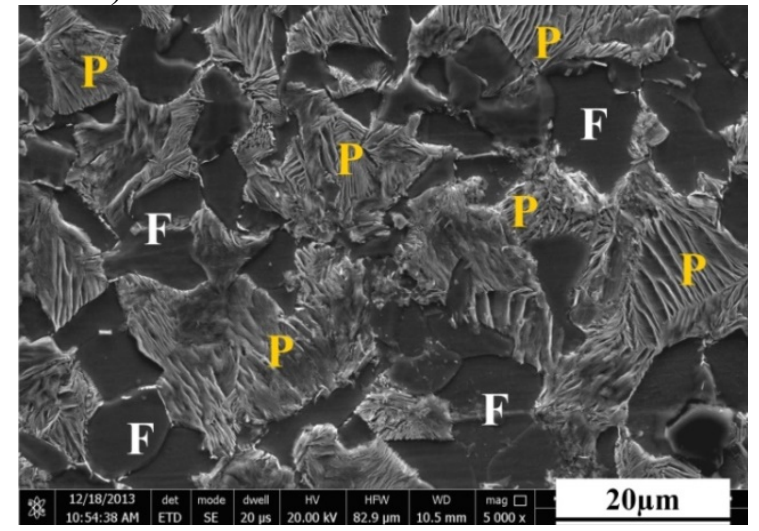

Fig. 4. SEM microstructure of hot forged air cooled steel alloys, (a) ST1 and (b) ST2; F is ferrite, P is pearlite and B is bainite phase

Table 3. Effect of Al content on the phase volume fraction of hot forged steels, \%

\begin{tabular}{|c|c|c|c|}
\hline & Ferrite $(\mathrm{F})$ & Pearlite $(\mathrm{P})$ & Binaite $(\mathrm{B})$ \\
\hline ST1 (1\%Al) & 5 & 15 & 80 \\
\hline ST2 $(2 \% \mathrm{Al})$ & 40 & 60 & -- \\
\hline
\end{tabular}

The X-ray diffraction and intensity of planes

The X-ray diffraction in Fig. 5(a) shows relatively high peaks and smooth background due to coarse grains of the as-cast structure. On the other hand, Fig. 5(b) shows relatively low peaks and very rough background for the hot forged structure due to high amount of deformation (high grain refinement). The intensity of the different planes for the as-cast and the hot forged air cooled steel alloys is shown in Fig.6. Increasing the Al percentage (in the as cast condition) does not exhibit a significant change of the x-ray peaks. However, the hot forging process highly changes the intensity of the (110) dominant plane. The intensity of (110) plane of the hot forged steel alloys decreased to almost half compared with the as-cast alloys as demonstrated in Fig.6.

a)

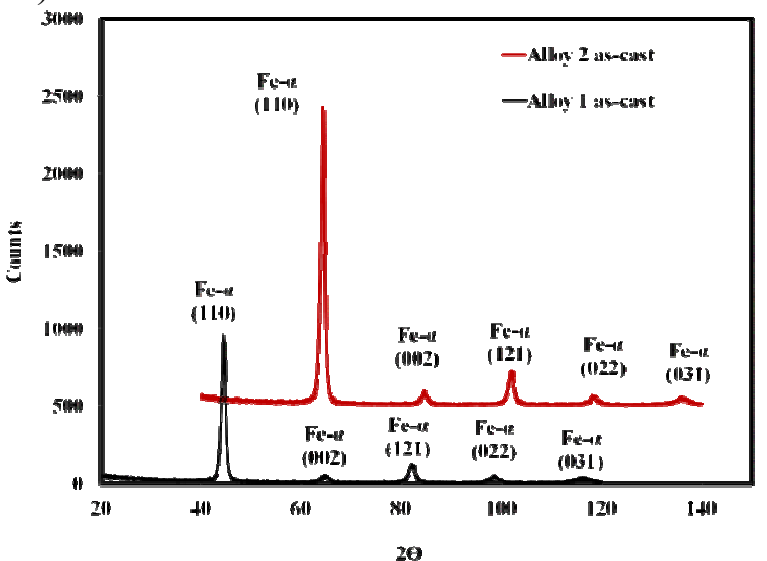

b)

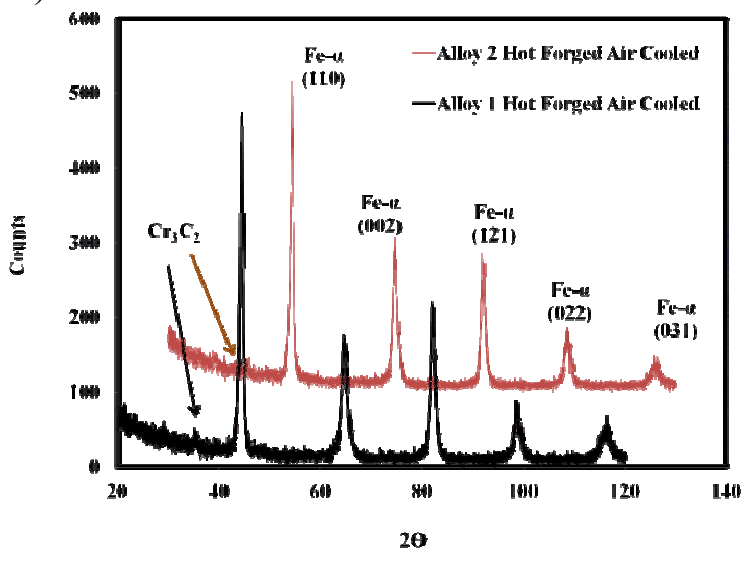

Fig. 5. X-ray diffraction of (a) the as-cast steel alloys and (b) hot forged steel alloys 
Also, the other planes relatively increased at the expense of the (110) plane as well as chromium carbides that had appeared for hot forged alloys compared with as cast alloys (see Fig. 5 and Fig. 6).

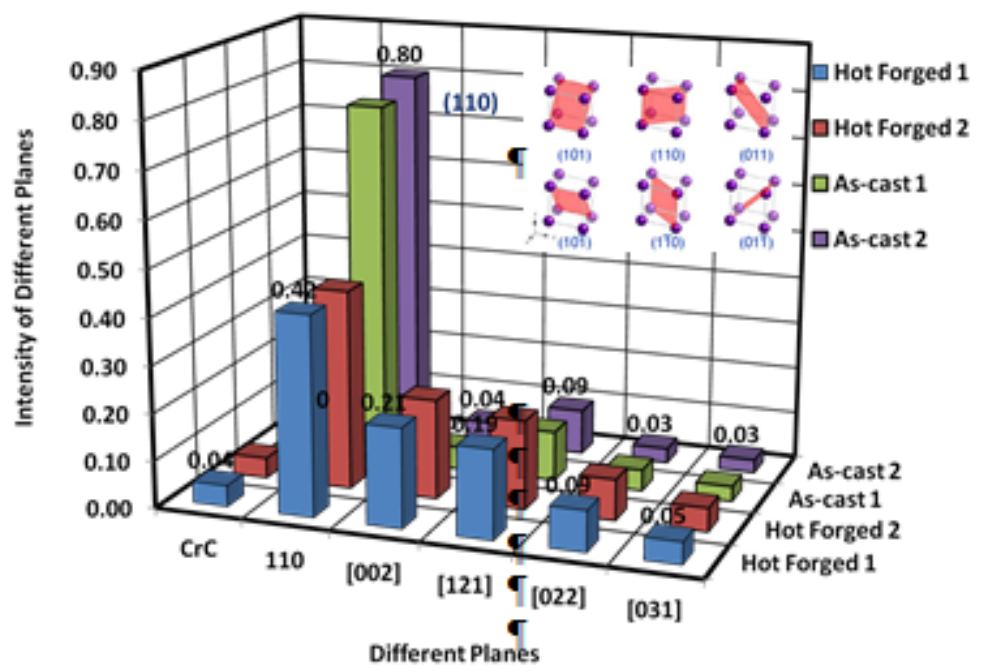

Fig. 6. Intensity of different planes for the as-cast and hot forged air cooled alloys 1 and 2

\section{Effect of austenitizing temperatures on the hot forged steel}

Figure 7 demonstrates the effect of different austenitizing temperatures on the final microstructure after water quenching. It is clear that ST1 exhibits dual phase steel containing bainite matrix and ferrite upon heating to $850^{\circ} \mathrm{C}$ for 15 minutes followed by water quenching. On the other hand, ST2 exhibits dual phase structure containing bainite and a lot of ferrite until heating to $900^{\circ} \mathrm{C}$ for 15 minutes followed by water quenching. This increase in the temperature range of dual phase structure for ST2 is due to increasing the Al content which encourages the ferrite formation. Upon increasing the austenitizing temperature up to $925^{\circ} \mathrm{C}$, it was found that ST1 produces a fully martensitic matrix giving the highest hardness value of $649 \mathrm{HV}$ as emphasized in Fig.8. With further increase in austenitizing temperature the hardness of ST1 gradually decreased due to the formation of tempered martensite. On the other hand, the highest hardness value recorded for ST2 is $531 \mathrm{Hv}$ at temperature of $1000^{\circ} \mathrm{C}$. This slight decrease is due to the formation of martensite matrix containing a very small amount of fine ferrite. Upon heating to $1100^{\circ} \mathrm{C} \mathrm{ST} 1$ and ST2 produce tempered martensite matrix revealing a decrease of hardness values. This decrease in hardness of ST2 could be attributed to the high amount of ferrite phase as a result of the increased aluminum content of the alloy. Finally, the heat treatment of hot forged ST1and ST2 revealed remarkable change in microstructure and in the hardness as well. It can be concluded that the hardness increases with increasing the temperature to maximum then decreased with farther temperature increase for both ST1 and ST2. Steel type 2 containing $2 \%$ aluminum revealed the maximum hardness of $649 \mathrm{Hv}$ compared with $531 \mathrm{Hv}$ maximum hardness of ST1 containing 1\% aluminum. As it is well known, aluminum enhances the ferrite phase formation. As ferrite is soft and ductile phase, it is responsible for decreasing the 
hardness and strength of ST2. The results of microstructure and hardness values are in a good agreement to explain the aluminum effect on steel properties.
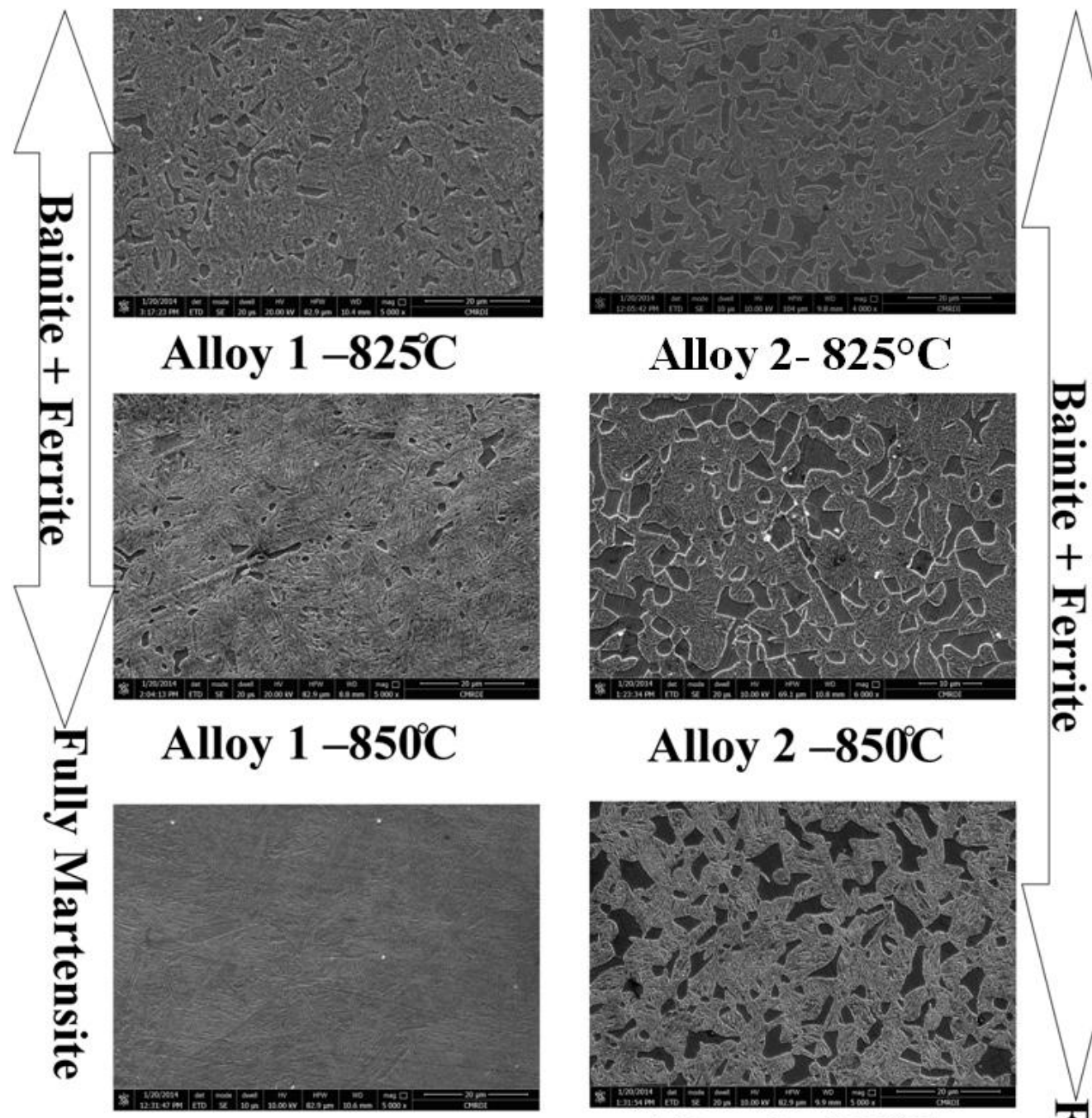

Alloy $1-900^{\circ} \mathrm{C}$

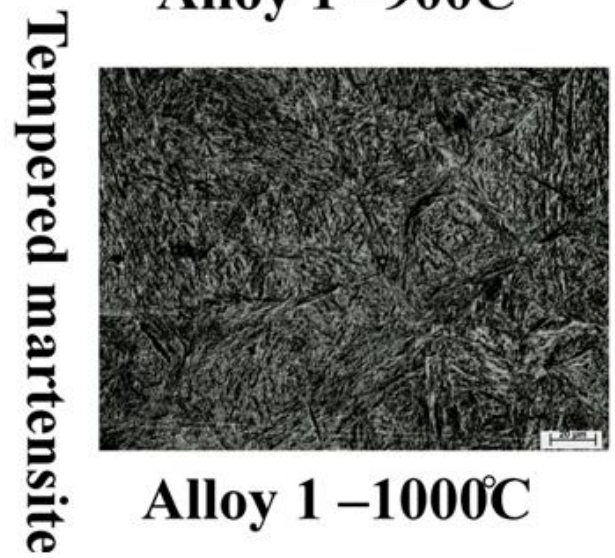

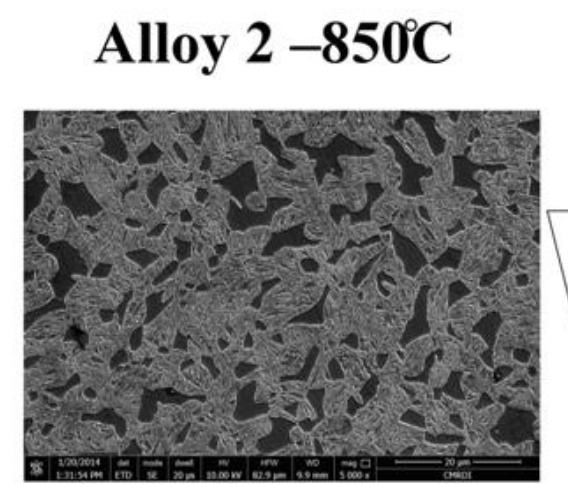
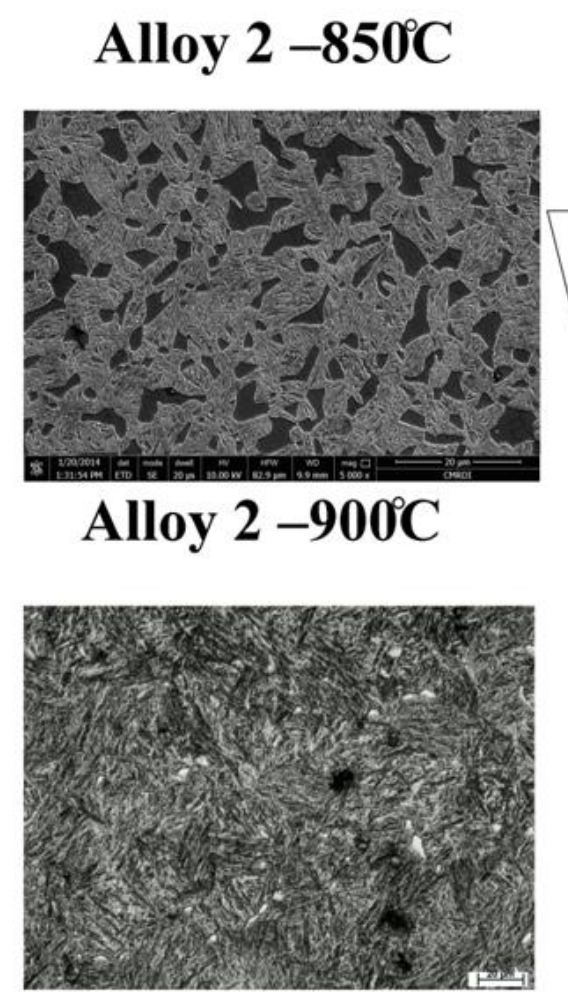

Alloy 2-1000'C

Alloy 2- $825^{\circ} \mathrm{C}$

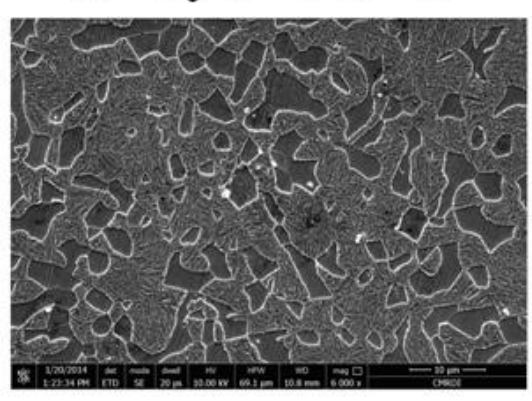

?

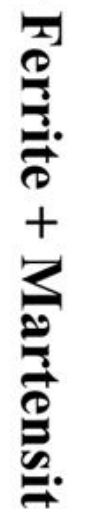

Fig. 7. Effect of austenitizing temperatures on the microstructure for hot forged ST1and ST2 


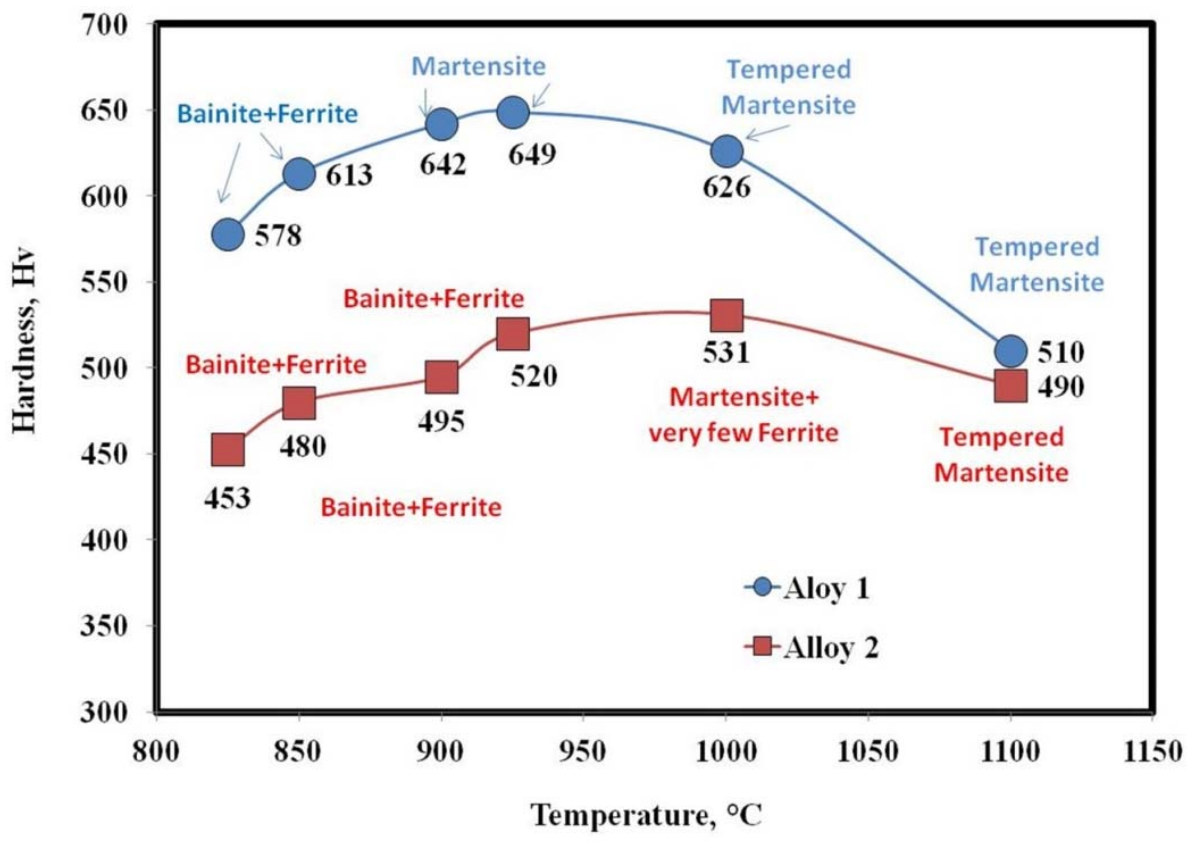

Fig. 8. Effect of austenitizing temperature on the hardness for ST1and ST2

\section{Effect of aluminum content on mechanical properties}

The engineering stress-strain curves after hot forging and air cooled ST1 and ST2 are presented in Fig.9. Generally, the tensile strength decreases by increasing aluminum content for the hot forged steel alloys. The maximum tensile strength was 1060MPa for ST1 and 940MPa for ST2. The yield strength was $700 \mathrm{MPa}$ for ST1 and 645MPa for ST2, see Table 3. It was found that the ductility had slightly increased with the increase in the aluminum content, which encouraged the ferrite phase formation. Table 4 summarized the mechanical properties of hot forged air cooled ST1and ST2. In contrast, the tensile test results support the results obtained from hardness test and microscopic investigation of ST1 and ST2. In other words, the behavior of hot forged steel is remarkably changed by the effect of aluminum content.

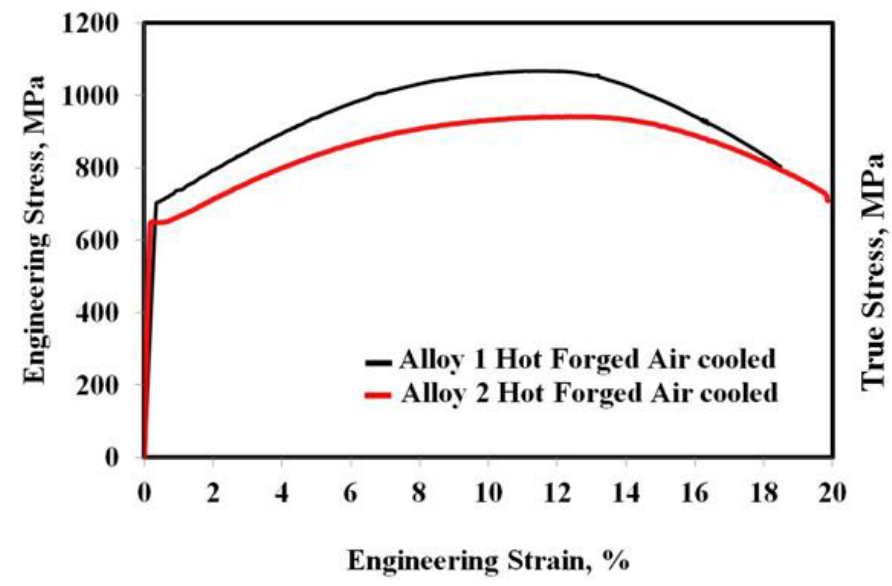

Fig. 9. Engineering stress-strain curves for ST1 and ST2 after hot forging and air cooling 
Table 4. Mechanical properties of hot forged air cooled steel ST1\& ST2

\begin{tabular}{|l|c|c|}
\hline Properties & Alloy1 (ST1) & Alloy2 (ST2) \\
\hline Yield Strength (YS), MPa & 700 & 645 \\
\hline Ultimate Tensile Strength (UTS), MPa & 1060 & 940 \\
\hline Total Elongation, \% & 18.46 & 19.88 \\
\hline Uniform Elongation, \% & 12 & 12.38 \\
\hline
\end{tabular}

\section{CONCLUSION}

Two medium carbon steel alloys containing different aluminum contents (ST1 and ST2) were used in this study after hot forging and compared with as cast steels. SEM microstructure revealed a matrix of bainite and pearlite and traces of ferrite for hot forged steel ST1 of 1\% Al. Hot forged ST2 of 2\% Al showed a matrix of pearlite and ferrite with the absence of bainite. It can be concluded that increasing aluminum content highly affects the microstructure of hot forged steel alloys. Increasing aluminum content highly increases the ferrite volume fraction. In the as cast condition, increasing the $\mathrm{Al}$ percentage does not exhibit a change of the $\mathrm{x}$-ray peaks. However, the dominant plane (110) intensity of hot forged alloys decreased to half values compared with the as-cast alloys. The hardness increases with increasing the temperature to maximum then decreased for both ST1 and ST2. The maximum hardness for ST2 containing $2 \%$ aluminum was recorded as $649 \mathrm{Hv}$ (at $925^{\circ} \mathrm{C}$ ), while the maximum hardness value for ST1 containing $1 \%$ aluminum was $531 \mathrm{Hv}$ (at $1000^{\circ} \mathrm{C}$ ). The maximum tensile strength was $1060 \mathrm{MPa}$ and $940 \mathrm{MPa}$ for hot forged ST1 and ST2, respectively. Finally, the microstructure and mechanical properties remarkably affected by the effects of aluminum increase in the hot forged steel alloys.

\section{ACKNOWLEDGMENTS}

The authors wish to acknowledge the approval and the support of this research study by the grant no. 04-03-1436-05 from the Deanship of Scientific Research in Northern Border University, Arar-KSA.

\section{REFERENCES}

1. Nürnberger F., Grydin O., Yu Z., Schaper M., Microstructural Behavior of Tempering Steels during Precision Forging and Quenching from Hot-forming Temperatures. Metallurgical and Mining Industry 3 (2011) 79-86.

2. El-Bitar T., Fouad N., Zaky A. I., El-Rady S.A., Effect of cooling rate after controlled forging on properties of low carbon multi-microalloyed steels. Materials Science and Engineering A 534 (2012) 514- 520. 
3. Zhuang L., Di W., Influence of Hot Deformation and Subsequent Austempering on the Mechanical Properties of Hot Rolled Multiphase Steel, J. Mater. Sci. Technol. 22 (2006) 763-768.

4. Radwañski G., Microstructural Comparison of the Thermomechanically Treated and Cold Deformed Nb-Microalloyed Trip Steel, Materials and Technology 48 (2014) 679-683.

5. Lourençoa N.J., Jorge Jr.a A.M., Rollob J.M.A., Balancina O., Plastic Behavior of Medium Carbon Vanadium Microalloyed Steel at Temperatures Near $\gamma \Leftrightarrow \alpha$ Transformation, Materials Research 4 (2001) 149-156.

6. Mazaheri Y., Kermanpur A., Najafizadeh A., Saeidi N., Effects of initial microstructure and thermo mechanical processing parameters on microstructures and mechanical properties of ultrafine grained dual phase steels, Materials Science \& Engineering A 61 (2014) 254-262.

7. Long X.Y., Kang J., Lvb B., Zhang F.C., Carbide-free bainite in medium carbon steel, Materials and Design, Materials and Design 64 (2014) 237-245.

8. Sharma S., Sangal S., Mondal K., Development of New High-Strength Carbide-Free Bainitic Steels, Metallurgical and Materials Transactions A 42A (2011) 3916-3921.

9. Lan H.F., Du L.X., Misra R.D.K., Effect of Microstructural Constituents on Strength-Toughness Combination in a Low Carbon Bainitic Steel, Materials Science \& Engineering A 611 (2014) 194-200.

10.Sandvik B.P.J, Nevalainen H.P, Structure-property relationships in commercial low-alloy bainiticaustenitic steel with high strength, ductility, and toughness, Material Science and Technology 8 (1981) 213-220.

11.Garcia-Mateo C., Caballero F.G., Bhadeshia H.K.D.H., Development of hard bainite, ISIJ International 43 (2003) 1238-1243.

12.Caballero F.G., Bhadeshia H.K.D.H., Very strong bainite. Solid State Material Science 8 (2004) 251257.

13.Caballero F.G., Bhadeshia H.K.D.H., Mawella K.J.A., Jones D.G., Brown P., Very strong low temperature bainite. Material Science and Technology 18 (2002) 279-284.

14.Garcia-Mateo C., Caballero F.G., Bhadeshia H.K.D.H., Acceleration of low temperature bainite, ISIJ International 43 (2003) 1821-1825.

15. Hase K., Garcia-Mateo C., Bhadeshia H.K.D.H., Bimodal size-distribution of bainite plates. Material Science \& Engineering A 438 (2006) 145-148.

16. Wang T.S., Li X.Y., Zhang F.C., Zheng Y.Z., Microstructures and mechanical properties of 60Si2CrVA steel by isothermal transformation at low temperature. Material Science \& Engineering A 440 (2006) 1124-1127.

17. Yang J., Wang T.S., Zhang B., Zhang F.C., Microstructure and mechanical properties of high-carbon Si-Al-rich steel by low-temperature austempering. Material \& Design 35 (2012) 170-184.

18. Soliman M., Palkowski H., Ultra-fine bainite structure in hypo-eutectoid steels, ISIJ International 47 (2007) 1703-1710.

19. Huang H., Sherif M.Y., Rivera-Díaz-del-Castillo P.E.J., Combinatorial optimization of carbide-free bainitic nanostructures, Acta Metallurgical 61 (2013) 1639-1647.

20. Masoud I. M., Farahat A.I.Z., AL-Jarrah J. A., Abu Mansour T., Thermo-Mechanical Processing of Carbide Free Steels, International Journal of Mechanical Engineering (IJME), 3 (2014) 37-44. 